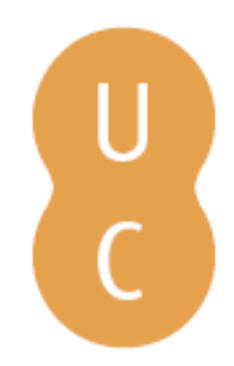

\title{
pompalina
}

\section{A historiografia contemporânea e as ciências da matéria: uma longa rota cheia de percalços}

\author{
Autor(es): \\ Alfonso-Goldfarb, Ana Maria; Ferraz, Márcia Helena M.; Beltran, Maria \\ $\mathrm{H}$. \\ Publicado por: Imprensa da Universidade de Coimbra \\ URL \\ persistente: \\ URl:http://hdl.handle.net/10316.2/32393 \\ DOI: \\ DOI:http://dx.doi.org/10.14195/978-989-26-0469-5_12 \\ Accessed : $\quad$ 26-Apr-2023 10:55:58
}

A navegação consulta e descarregamento dos títulos inseridos nas Bibliotecas Digitais UC Digitalis, UC Pombalina e UC Impactum, pressupõem a aceitação plena e sem reservas dos Termos e Condições de Uso destas Bibliotecas Digitais, disponíveis em https://digitalis.uc.pt/pt-pt/termos.

Conforme exposto nos referidos Termos e Condições de Uso, o descarregamento de títulos de acesso restrito requer uma licença válida de autorização devendo o utilizador aceder ao(s) documento(s) a partir de um endereço de IP da instituição detentora da supramencionada licença.

Ao utilizador é apenas permitido o descarregamento para uso pessoal, pelo que o emprego do(s) título(s) descarregado(s) para outro fim, designadamente comercial, carece de autorização do respetivo autor ou editor da obra.

Na medida em que todas as obras da UC Digitalis se encontram protegidas pelo Código do Direito de Autor e Direitos Conexos e demais legislação aplicável, toda a cópia, parcial ou total, deste documento, nos casos em que é legalmente admitida, deverá conter ou fazer-se acompanhar por este aviso.

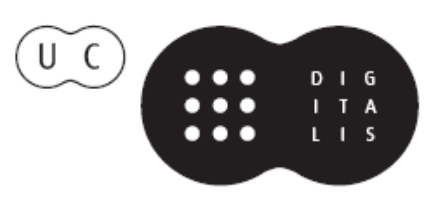


Ana Leunar Pereira João Rui Pita

[ Coordenaçä̃ ]
Rotas da Natureza

Cientistas

Viagens

Expedifgũes

Instituip̧ües

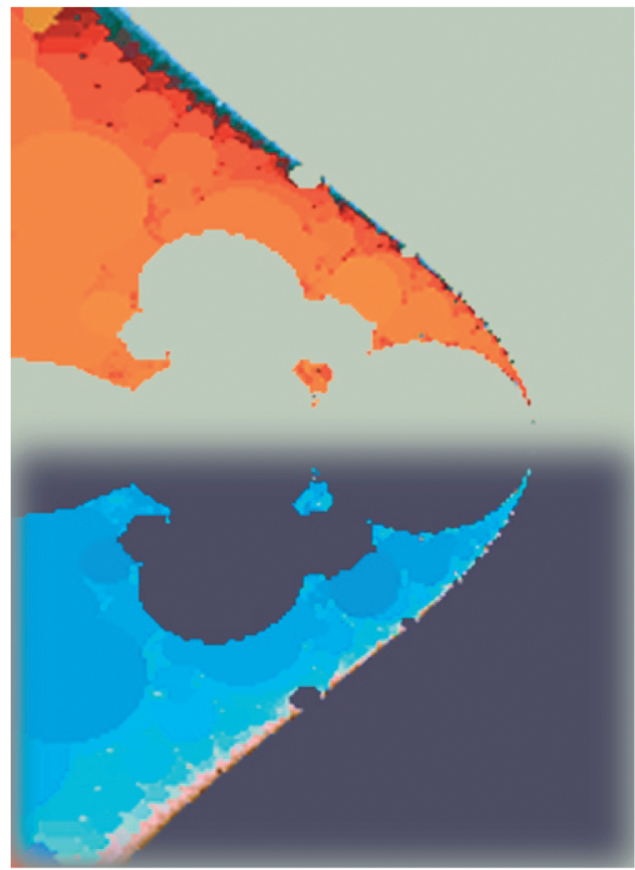




\section{Coordenaçáo Científica da Colecção Ciências e Culturas}

João Rui Pita e Ana Leonor Pereira

Os originais enviados são sujeitos a apreciação científica por referees

\section{Coordenação Editorial}

Maria João Padez Ferreira de Castro

\section{Edição}

Imprensa da Universidade de Coimbra

Email:impresauc@ci.uc.pt

URL: http://www.imp.uc.pt • Normas de publicação de colecçôes

\section{Design}

António Barros

Pré-Impressáo

António Resende

Imprensa da Universidade de Coimbra

\section{Capa}

António Barros, com imagem de E. M. de Melo e Castro, 2003 [Fractal original gerado no Fractint com tratamento no Photoshop 7.0]; Cortesia: António Barros

Impressão e Acabamento

SerSilito • Maia

\section{ISBN}

978-989-8074-12-6

\section{Depósito Legal}

Obra publicada com a colaboraçáo de:
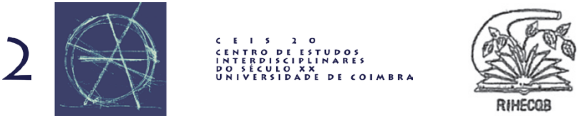

Obra publicada com o apoio de:

FCT Fundação para a Ciência e a Tecnologia

MINISTÉRIO DA CIÊNCIA, TECNOLOGIA E ENSINO SUPERTOR Portug

Programa Operacional Ciência, Tecnologia, Inovação do Quadro Comunitário de Apoio III
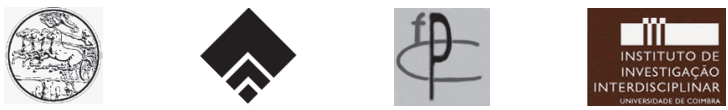

\section{Baxter}

(c) 2006, Imprensa da Universidade de Coimbra 
João Rui Pita

Ana Leonar Pereira

(Courdenação)

Rotas da Natureza

Cientistas

Viagens

Expediçũes

Instituiç̃̃es

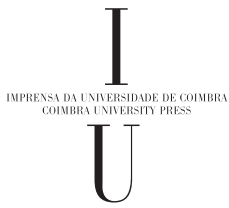

- colmbra 2006 
(Página deixada propositadamente em branco) 
Ana Maria Alfonso-Goldfarb ; Márcia Helena M. Ferraz ; Maria H. Beltran

Pontifícia Universidade Católica de São Paulo;

Programa de Estudos Pós-Graduados em História da Ciência;

Centro Simão Mathias de Estudos em História da Ciência, Brasil

\section{A Historiografia CONTEMPORÂNEA E AS CIÊNCIAS dA MATÉRIA: UMA LONGA ROTA CHEIA DE PERCALÇOS}

Em setembro de 1957, um grupo de estudiosos reuniu-se para discutir o labirinto de caminhos e questôes em que penetrara a história da ciência. Abrigados sob grandes temas tradicionais, pensadores tão distintos como M. Clagett, R. Merton, T. Kuhn e o casal M. Boas e R. Hall, debateram, durante 10 longos dias, suas divergentes concepçōes sobre teoria/práxis; ciência/sociedade; revolução/revoluçōes continuidades nas ciências e outras questôes espinhosas na área. Expressos nas páginas do hoje clássico Critical Problems in the History of Science, esses debates refletiam profundas diferenças no fazer, pensar e ensinar história da ciência entre cada autor ou grupo de autores. $\mathrm{Ou}$, em poucas palavras: as divergências eram de natureza historiográfica.

Todavia, para melhor refletir sobre essas divergências, voltemos as primeiras décadas do século XX quando se deu a gestação de um espaço autônomo para a história da ciência. Entre as perspectivas metodológicas e historiográficas então surgidas irá se destacar, tornando-se hegemônica, aquela que teve como principal articulador G. Sarton.

Figura central na institucionalização da história da ciência, Sarton será o fundador e, por muitos anos, o editor de Isis - periódico exclusivamente dedicado à área e até hoje um dos mais respeitados. Não por acaso, o modelo seguido por esse pioneiro iria se perpetuar por longo tempo.

Era esse um modelo baseado nas tendências epistemológicas da virada do século, contemplando idéias de estudiosos como E. Mach e P. Duhem e pressupondo o desenvolvimento contínuo e acumulativo da ciência. Um processo considerado único, progressivo e inevitável, pois teria seguido a trilha lógica das verdades sobre a natureza. Acreditava-se que esse processo tivesse sido atrasado ou interrompido várias vezes por contingências históricas, mas que ao pairar acima destas fora sempre retomado, alcançando um patamar estável de crescimento com a ciência moderna.

Em linhas gerais, a Grécia antiga era vista como o berço onde acontecera a primeira infância da ciência. Esta teria vivido uma instável juventude durante o Medievo e o Renascimento, atingindo o início de sua maturidade no século XVII - sobretudo a partir das teorias de Copérnico, Galileu e Newton. Aliás, as chamadas «ciências exatas» - mais precisamente as ciências físicas - e destas a face teórica, constituíam a base sobre a qual eram mensuradas as demais ciências do passado. 
Sem dúvida, o modelo continuísta obrigava a ciência a olhar para a história, pois sem ela, segundo afirmava Sarton, seria: «...como se conhecêssemos um homem já na idade madura, sem que nos apercebêssemos de que tal maturidade foi possível graças aos longos anos de infância e adolescência.» Mas, por outro lado, esse era um modelo intrinsecamente anacrônico, que pressupunha todo o conhecimento passado objetivando o presente e, portanto, criava uma interminável linhagem de "precursores» ou «pais» da ciência.

De qualquer modo, entre as décadas de 30 e 40, esse modelo continuísta, baseado na evolução interna das teorias sobre a natureza, permaneceu como paradigmático em história da ciência. Os grandes compêndios de A. Mieli, A. Rey e do próprio Sarton foram a expressão mais bem acabada desse tipo de historiografia.

Todavia, em torno a esse período, várias tendências divergentes irão ganhar corpo. A corrente denominada externalista, estabelecida por estudiosos como B. Hessen, J. D. Bernal e J. Needham, passa a considerar o desenvolvimento da ciência numa perspectiva social e política. Além disso, passa a haver uma adesão cada vez maior a teses como a de L. Thorndike que, por exemplo, sem abandonar o enfoque interno à ciência, pensava a sua transformação a partir de uma perspectiva operativista, abrindo um leque histórico desde a magia até o experimentalismo. Também nessa época, a partir dos trabalhos de E. Burtt e G. Bachelard, começa a tomar forma uma perspectiva descontinuísta e, portanto - mais do que divergente - oposta à de Sarton.

A crescente aceitação de que a ciência não se desenvolvera necessariamente de forma homogênea e acumulativa, e de que fatores externos pudessem ter interferido nesse processo, afastou cada vez mais, nas décadas seguintes, a produção em história da ciência das diretrizes estabelecidas por Sarton. Tudo indica, porém, que a ruptura definitiva com a historiografia continuísta tenha se dado nos anos 60 , gerada, sobretudo, pelo debate em torno da obra de T. S. Kuhn. Muito embora tenha sido considerado relativista e pouco preciso em suas teses, Kuhn desmontou de forma radical as bases do continuísmo. Mesmo vaga, sua definição de ciência pré-paradigmática e paradigmática deu conta das possíveis rupturas no processo do conhecimento, permitindo observar a incomensurabilidade entre as teorias dos diferentes períodos. Introduziu-se, assim, de uma vez por todas a questão do contexto, já no nível conceitual das teorias, eliminando do panorama da história da ciência as incômodas e artificiais linhagens de "precursores».

Entretanto, ao pretender-se muito abrangente e afastar-se de forma radical do modelo continuísta e ad tempore, o modelo kuhniano acaba produzindo uma série de problemas. $\mathrm{O}$ excessivo descontinuísmo assumido por esse modelo não permitiu, por exemplo, avaliar a tendência à continuidade que parece ter existido tradicionalmente na praxis da ciência, mesmo nos momentos em que as teorias passavam por reformulação. Além disso, há indicações claras de que Kuhn tenha apoiado sua definição de ciência paradigmática nas ciências físicas. Assim, ao estender essa definição a outras ciências, acabou impondo um modelo pouco adequado às singularidades destas, desvalorizando suas histórias pré-modernas - que em geral considerava pré-paradigmáticas - e tornando muitas vezes incompreensível a sua inserção na modernidade.

Em todo caso, o estabelecimento de um modelo descontinuísta abrangente forçou, a partir dos anos 70, a revisão profunda do modelo tradicional, o que auxiliou a gerar uma nova corrente historiográfica que até hoje vem se desenvolvendo. Essa nova historiografia teve como princípio não só a observação pontual e minuciosa de estudos 
de caso, mas também as variantes regionais e circunstanciais que os envolveram e particularizaram dentro do contexto mais geral ao qual pertenciam.

Fundamental para a tessitura dessa nova historiografia foi a assimilação de estudos como o de W. Pagel e F. Yates que, já nos anos 60, corriam paralelos às vias hegemônicas da história da ciência. Muito embora a partir de abordagens distintas, tanto Pagel quanto Yates propunham: (I) a difusão, para outras áreas do saber, do foco centrado sobre as ciências físicas e seus personagens principais. (II) a diluição das linhas entre as chamadas "proto" e "pré» ciências, bem como entre estas e a ciência moderna em suas origens. Através desses estudos, vários dos conhecimentos esquecidos, exilados ou mesmo deformados pela história da ciência, passavam a ter dimensão e relevância, até então insuspeitados, no quadro dos saberes sobre a natureza.

Os contornos desse novo quadro historiográfico, foram delineados de forma magistral por G. Canguilhem quando nos diz:

"Convém reconhecer como indispensável uma boa utilização da recorrência e uma educação da atenção às rupturas (...). A epistemologia da continuidade encontra nos começos ou no despertar de um saber os objectos de sua preferência. A epistemologia das rupturas de modo algum despreza a epistemologia da continuidade, mesmo quando faz ironia sobre os filósofos que só acreditam nesta...»

Com os olhos postos nesse quadro - que já insinuava articulações inéditas - a nova historiografia desenvolveu um processo de análise não continuísta, portanto, sem ler o passado a partir do presente; mas também evitando a imposição generalizada de fórmulas descontinuístas. A tônica desse processo, conforme já indicado, recai inicialmente sobre a especificidade de casos e documentos - suas fontes, suas singularidades, seus vínculos e ecos locais - para só depois traçar as relações destes com um contexto mais amplo. Trata-se de uma análise de mão dupla, que perpassa as diversas camadas de texto e contexto. Sua realização vem utilizando elementos de filologia, arqueologia, semiótica, antropologia, das histórias do livro e das artes e ofícios, além das já tradicionais histórias da cultura, do pensamento e da sócio-política. Desta maneira, tem se formado um mapa temporal da ciência, extremamente complexo, onde convivem rupturas e permanências, e onde é possível estabelecer pressupostos que extrapolam os modelos historiográficos convencionais.

Estudiosos como A. Debus, B. J. Dobbs, G. E. R. Lloyd, P. Rossi, P. Rattansi, B. Copenhaver e W. Shea - responsáveis por boa parte do traçado original desse mapa - redimensionaram as vias preferenciais da ciência, associando a estas, por exemplo, vieses religiosos, herméticos, neoplatônicos, bem como uma releitura dos aristotelismos guardando as singularidades de seus leitores ou grupos de leitores nos contextos das diferentes épocas. Vieses estes que foram de grande importância até, pelo menos, o século XVIII.

\section{Reflexos das transformações historiográficas na ciência da materia}

Como seria de se esperar, na historiografia que trata da ciência da matéria também se observa um movimento semelhante ao acima descrito. Trabalhos sérios desenvolvidos pelo menos desde o início de nosso século XX, tais como os de E. O. von Lippman, 
J. Ruska, e P. Diepgen acabaram por gerar uma escola de estudiosos que baseava seus trabalhos no modelo continuísta ou ad tempore. Partindo da ciência helênica e, em especial do aristotelismo, um fio vermelho seguia de modo linear e cumulativo, fazendo com que a ciência antiga, cuja noção de matéria estava baseada em qualidades e humores, parecesse uma etapa prévia e incipiente da ciência moderna. Traçava-se assim um passado a partir do presente, no qual as concepçōes de precursor, pré-história, e predeterminação eram inevitáveis.

Em sua maioria, esses estudos destacavam as práticas de laboratório e seus materiais, assim como os processos de intervenção e observação de fenômenos naturais, na medida em que esses, de alguma maneira, pudessem ser comparados a procedimentos modernos. De tal sorte que acabava por se dar uma fragmentação das obras e das teorias estudadas, lançando à sombra do esquecimento histórico porções fundamentais a seu entendimento. Arrancadas de seu contexto, certas partes das obras eram apresentadas como velhos receituários de cozinha ou sortilégios de antigos feiticeiros, enquanto outras eram vistas como prenúncio da ciência da matéria moderna - colocando palavras e intenções inexistentes na boca de seus autores.

$\mathrm{Na}$ verdade, buscando as origens de sua própria disciplina, os estudiosos continuístas romperam, muitas vezes, as complexas relações traçadas por autores antigos, pinçando e selecionando idéias, conceitos e receituários que acreditavam diretamente ligados a suas respectivas especialidades modernas. Grandes pensadores do passado como Ar-Razi ou Arnaldo de Villanova, por exemplo, foram apresentados de forma completamente distinta pela história da química e pela história da medicina. Não raro, aliás, ao longo desse processo seletivo, se chegava a versões diferentes e até conflituosas sobre um mesmo autor ou uma mesma teoria. Enquanto a primeira via nas obras alquímicas significativas desses autores uma grande contribuição para a ciência da matéria, a segunda considerava tais obras como apócrifas ou minimizava a sua importância em termos de ciências da vida.

Neste, como em outros casos, as análises continuístas consideravam antigas obras - complementares ou polimáticas em sua origem distante - projetando sobre elas imagens que pertenceram, de fato, aos séculos XVIII e XIX. Pois somente nesse período os estudos sobre a matéria bruta e aqueles sobre a matéria viva foram contrapostos e correram por vias separadas rumo à especialização.

A historiografia relacionada à ciência da matéria, sem dúvida, irá sofrer profundas modificaçôes a partir da assimilação das teses descontinuístas. Entre os anos 50 e início dos 60, mesmo antes do grande impacto causado pelas idéias de T. S. Kuhn, começam a surgir trabalhos como os de E. J. Dijksterhuis, M. Boas e M. P. Crosland, formando a base principal das concepções sobre a chamada "revolução científica», no que tange às ciências da matéria. Ao aceitar a idéia de que teria havido uma transformação radical entre os séculos XVI e XVII, esses estudiosos sugerem um antes e um depois para a ciência da matéria. Pois, em torno a esse período, entre as várias transformaçôes radicais teria ocorrido a substituição da ciência das qualidades por uma ciência quantitativa e mecanicista.

Todavia, o processo histórico em que se deu a transição do modelo de matéria antigo para o novo resistiu em vários pontos às análises descontinuístas. Efetivamente, a nova concepção mecanicista fora uma das bases da chamada "revolução científica». Mas, campos importantes do saber, como por exemplo, medicina, história natural, 
química e farmácia, mantiveram uma concepção qualitativa, até finais do século XVIII e princípios do XIX. E, quando, finalmente, se adota nesses campos uma nova concepção da matéria, esta já não será mais a mecanicista.

De igual maneira, as análises descontinuístas não conseguiram dar conta da permanência de debates antigos - como, por exemplo, sobre o natural e o artificial - que deveriam ter desaparecido com a argumentação da concepção mecanicista.

Nas últimas décadas, a nova historiografia vem retomando essas questōes, visando introduzir a ciência da matéria num panorama que contemple a relação entre rupturas e permanências e respeite a complexidade dos documentos históricos, como queria Canguilhem. Nesse sentido, os trabalhos de B. J. Dobbs e W. Shea, que analisaram respectivamente as obras de Newton e Descartes, conseguiram captar uma topografia heterogênea, onde permanência e descontinuidade conviveram lado a lado. Enquanto estudiosos como A. G. Debus, P. Rattansi e G. Lloyd fizeram levantamento das correntes submersas na ciência hegemônica, e que parecem ter sido base importante para sua transformação. Mais recentemente, diversas publicações coletivas vêm tentando discutir o tema, tais como: Reading the Book of Nature: The other Side of Scientific Revolution, organizado por A. G. Debus e M.T. Walton; Repraisals of Scientific Revolution, sob a direção de D.C. Lindberg e R.S. Westman e, ainda Rethinking the Scientific Revolution, organizado por M.J. Osler.

Essas obras tentam refletir a validade de se pensar em grandes rupturas (como a chamada 'revolução científica') ou se é possível falar em período 'revolucionário' estendido (na verdade, uma transformação gradual entre os séculos XVI e XVIII).

Em nosso caso particular, temos buscado identificar a topografia desse ir e voltar histórico. Como tradicionais historiadores das ciências da matéria, voltamos nossa atenção a análise de documentos por meio de crítica textual, considerando as raízes e as camadas dos textos. Enquanto, por outro lado, temos buscado - dentro de uma perspectiva mais recente - entender como vão desaparecendo esses focos e camadas textuais, a medida em que modifica-se o contexto e com este as concepçóes de cosmo.

Especificamente, temos usado como base documentos medievais de formulação poligráfica, derivados de antigas fontes, onde é possível verificar a coligação intrínseca dos vários saberes e o caráter qualitativo das ciências da matéria. Essa característica permanece visível ainda em textos renascentistas, que temos analisado, embora já se anuncie um princípio de desmembramento e classificação de temas específicos. E mais ainda, apesar de várias transformações radicais e palpáveis durante os séculos XVI e XVII, foi possível verificar em textos de vários estudiosos considerados iniciadores da ciência moderna, uma composição dos saberes formando um desenho à moda antiga, onde permanecem, mesmo sem querer, velhas concepções qualitativas. Um desmembramento mais evidente, foi verificado por nós em textos a partir do século XVIII, em trabalhos que tratam de separar as ciências que cuidam dos fenômenos com a matéria viva e aquelas dirigidas aos fenômenos da matéria bruta. Ainda assim, verifica-se, já em pleno século XIX, quando a separação e especificidade das ciências estaria sendo estabelecida, que a antiga visão qualitativa ainda permanece em textos dirigidos a procedimentos práticos, sejam de laboratório químico, dispensário médico ou botica. Ou como diria G. Canguilhem: «Numa trama histórica, alguns fios podem ser inteiramente novos, enquanto outros são tirados de texturas antigas». 


\section{Colecçãa \\ 2 Ciências e Culturas Caimbra 2006}

